This item was submitted to Loughborough's Research Repository by the author.

Items in Figshare are protected by copyright, with all rights reserved, unless otherwise indicated.

\title{
PLGA particle production for water soluble drug encapsulation: degradation and release behaviour
}

PLEASE CITE THE PUBLISHED VERSION

PUBLISHER

(c) Elsevier

VERSION

AM (Accepted Manuscript)

LICENCE

CC BY-NC-ND 4.0

\section{REPOSITORY RECORD}

Gasparini, G., R.G. Holdich, and S.R. Kosvintsev. 2009. "PLGA Particle Production for Water Soluble Drug Encapsulation: Degradation and Release Behaviour". figshare. https://hdl.handle.net/2134/5651. 
This item was submitted to Loughborough's Institutional Repository (https://dspace.lboro.ac.uk/) by the author and is made available under the following Creative Commons Licence conditions.

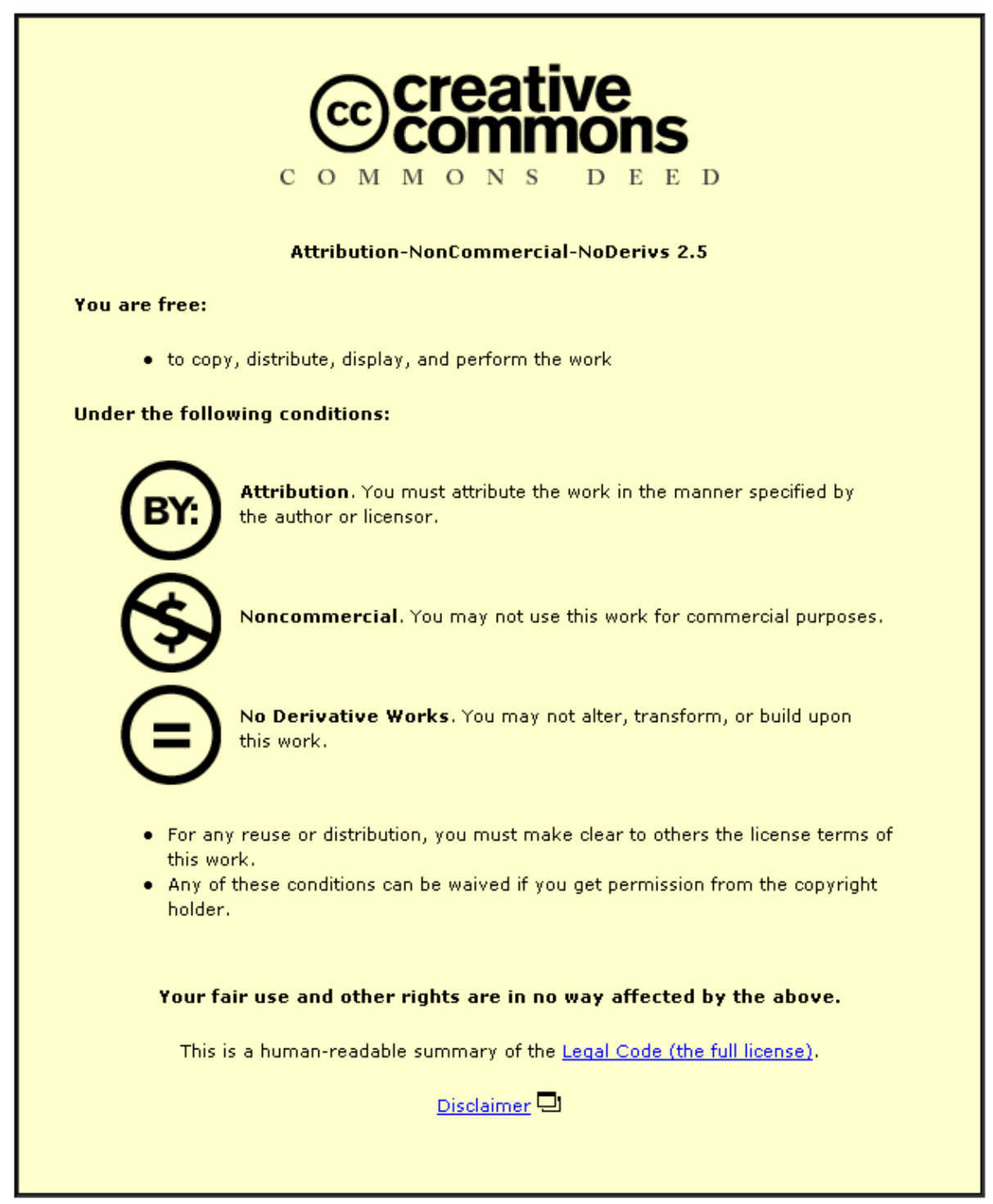

For the full text of this licence, please go to: http://creativecommons.org/licenses/by-nc-nd/2.5/ 


\title{
PLGA Particle Production for Water Soluble Drug Encapsulation:
}

\section{Degradation and Release Behaviour}

G. Gasparini ${ }^{a}$, R.G. Holdich ${ }^{a,{ }^{*}}$ and S.R. Kosvintsev ${ }^{\text {b }}$

${ }^{a}$ Department of Chemical Engineering, Loughborough University, Leicestershire, LE11 3TU, UK.

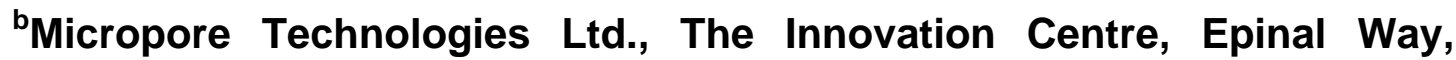
Loughborough, Leicestershire, LE11 3EH, UK.

*corresponding author: Tel: +44 1509 222519; fax: +44 1509 223923; Email: R.G.Holdich@Lboro.ac.uk

\begin{abstract}
Particles for subcutaneous depot use encapsulating a model water soluble drug have been produced from poly(lactic-glycolic acid) (PLGA) using a membrane emulsification - solvent evaporation technique. The release behaviour, mainly the change in size and inner morphology are reported. During release, the particles initially swelled in size, then reduced. A diffusion based model, taking in to account the change in particle size, is presented. Surface erosion is evident from the particle size and image evidence, and the diffusion model provides a fit to the data even during the surface erosion period, suggesting that the model drug diffuses before the particle degrades.
\end{abstract}

Keywords: membrane emulsification, diffusion, surface erosion 


\section{Introduction}

A comprehensively studied field in the pharmaceutical sector is controlled drug release from biodegradable polymer matrixes. Numerous researchers have focused on production of nanoparticles, which can be used for very fine spray inhalators, or intravenous injections. Larger particles, between 5 and 150 micrometres, are useful because they are large enough to remain at the site of injection and provide significant drug loading, but small enough to be administered through a relatively small-gauge hypodermic needle. This work used poly(d,I-lactide-glicolide acid), or PLGA, because of its versatility, availability, and well-known suitability as a controlled release biocompatible polymer.

The PLGA particles were produced by membrane emulsification followed by solvent evaporation and the membrane emulsification method followed here has been thoroughly described previously [1-5]. Specifically, its application for PLGA particle production has been reported [6], from which this work follows. For the emulsification step, other methods are available, such as: homogenizer, sonication [7-9] and stirring [10-14]. These are straightforward techniques, but it is difficult to control the size and size distribution of the drops. The SPG glass membrane [15-17] and vibrating nozzle [18-22] provide better control of size.

Building on the previous work [6], a range of monosized particles containing a water soluble model drug with high encapsulation efficiency were produced and exposed to release conditions in way not normally reported. Because of the relatively high quantity of particles produced, by employing the lamina surface membrane emulsification technique, it was possible to divide the 
particles in to ten independent samples, which were subjected to identical model drug release conditions. At regular intervals, one sample was analyzed while the others continued undisturbed. Not only the water medium was analyzed, but also the particles were tested and disposed of without disturbing the remaining particles under test. Results from the change in size of the particles during release are shown and a release model based on diffusion coupled to particle size change is proposed. In other studies, PLGA may degrade mainly through bulk erosion, [10, 23-27], however, the gradual size change and the images illustrated here suggest that, when encapsulating a water soluble drug by a water-in-oil-in-water $(\mathrm{W} / \mathrm{O} / \mathrm{W})$ emulsion, both surface and bulk erosion contribute to the polymer degradation.

\section{Materials and Methods}

To encapsulate a model water soluble drug, a double emulsification, W/O/W, was performed. Resomer RG 503H (d,I-lactide glicolide ratio 50/50) was obtained from Boehringer Ingelheim, Poly Vinyl Alcohol PVA (MW 25000, $88 \%$ degree of hydrolysis) and sodium chloride from Fisher, DiChloroMethane DCM from Acros and blue dextran 2000 from Pharmacia Fine Chemicals. For the release, phosphate buffer solution PBS tablets (Dulbecco A) from Oxoid and sodium azide from Sigma Aldrich were used. Reverse osmosis water was obtained from a Millipore unit.

The membrane emulsification apparatus was a dispersion cell provided by Micropore Technologies Ltd, Leicestershire, UK. The discontinuous phase was injected by a syringe pump at the base of the cell; it passed through the membrane, where the droplets are formed, into the continuous phase. The 
continuous phase was agitated by a two-bladed paddle controlled by a DC motor. The membrane was a thin flat metal disc with monosized circular pores distributed in a highly regular array. Three pore size membranes were used, 7,20 and $40 \mu \mathrm{m}$ in diameter, with the same pore distance equal to $200 \mu \mathrm{m}$. A more detailed description can be found elsewhere [1-6].

\section{Particle Production}

This study follows from an earlier one [6], where different solidification methods and a variety of operating conditions were considered in order to produce the required size of particles and enhance the encapsulation efficiency, $\varepsilon$.

Firstly $2.86 \mathrm{ml}$ of reverse osmosis water, $3000 \mathrm{ppm}$ of blue dextran and 40 (or 13) $\mathrm{g} / \mathrm{l}$ of salt were emulsified with $7.14 \mathrm{ml}$ of DCM and different concentrations of PLGA (5 to 15\%). The emulsification was performed by homogenization for thirty minutes (Silverson). This primary emulsion was the discontinuous phase for the secondary emulsification. For the second emulsification the Dispersion Cell was used. The discontinuous phase was injected into $150 \mathrm{ml}$ of reverse osmosis water containing $1 \%$ PVA, different salt concentrations (40 or $13 \mathrm{~g} / \mathrm{l}$ ) and the water was saturated in DCM. The injection rate was $0.5 \mathrm{ml} / \mathrm{min}$, the agitation speed was $600 \mathrm{rpm}$ when a $40 \mu \mathrm{m}$ membrane was used, and $860 \mathrm{rpm}$ for 20 and $7 \mu \mathrm{m}$ pore sized membranes. Once $10 \mathrm{ml}$ of discontinuous phase was injected, the double emulsion was poured in to a $400 \mathrm{ml}$ beaker (diameter equal to $8 \mathrm{~cm}$ ) and magnetically stirred overnight at $120 \mathrm{rpm}$ to remove the DCM and form the solidified particles. 
Blue dextran 2000 was chosen as the water-soluble model drug because it can be easily measured spectrophotometrically and has been used previously for PLGA microparticles [15]. See elsewhere [6] for the development of this method.

\section{Particle Characterization}

At the end of the emulsification process, three pictures were taken of the newly formed emulsion using an optical microscope. The emulsion droplets were not yet solid and they were not stable sufficiently to be analyzed using other particle size analysis methods. Up to 1000 droplets were size analyzed optically using Image J software.

After overnight stirring, the droplets became solid particles. Their size and size distribution were measured using a Malvern Mastersizer. A comparison of Image $\mathrm{J}$ and Malvern's data shows that the two methods provide similar results. When FEG-SEM (Carl Zeiss 1530 FEGSEM) pictures were taken, some of the particles were placed on a filter paper in a thin layer and left to dry overnight. The particles were finally gold coated before obtaining the scanning electron micrographs.

A sample from the outer water phase was filtered using a Whatman filter paper number three and analyzed by ultraviolet spectrophotometer at a wavelength of $620 \mathrm{~nm}$ ( UV/VIS Lambda 12, Perkin Elmer) to measure the presence of blue dextran 2000 that was not encapsulated.

\section{Drug Release Studies}

After the particle characterization analysis the particles were then filtered (Whatman filter paper number 3) and washed three times with reverse 
osmosis water. They were collected, without drying; not to expose them to harsh conditions. The particles were carefully equally separated into 10 samples. $25 \mathrm{ml}$ of PBS and $0.1 \%$ sodium azide solution was added to each sample. The bottles were sealed and placed in a warm shaking bath at 37 degrees Celsius and mildly agitated. At regular intervals, one sample was taken out of the bath. Pictures of the particles with an optical microscope and a FEG-SEM were taken to determine changes in morphology and size. The particle size and size distribution was measured by Malvern Mastersizer. The release medium was filtered and the presence of blue dextran was detected by ultraviolet spectrophotometer at a wavelength of $620 \mathrm{~nm}$.

\section{Results and Discussion}

In the previous work, [6], it was shown how PLGA concentration, membrane pore size and osmotic pressure affect particle size and encapsulation efficiency. Osmotic pressure was controlled by varying the concentrations of salt in the inner and outer water phases during particle production. This work reports the use of that information to produce the most suitable particles and extends the study of these parameters in to the drug release phase. The Dispersion Cell permits the production of a sizeable enough quantity of monosized particles so that it is possible to divide in to ten independent samples. Usually $[19,21,24,28]$ the release is studied by removing only the release medium and replacing it, without disturbing the particles, so as not to change their number, or otherwise influence their degradation. In this work, at regular intervals, a sample is taken out of the shaking bath and it can be completely analyzed. The remaining particles in the other samples continue 
the release process undisturbed. Hence, following this procedure, it is possible to monitor changes in size, size distribution and surface morphology of the particles during the release.

In Table 1, the characteristics of the particles used for the release studies are summarized. Different membrane pore diameters were tested in order to achieve particles of different sizes. Different PLGA and salt concentrations influence the particle morphology. The results are in line with what was expected from the previous study [6]. Blank particles (still W/O/W emulsions but without blue dextran) were produced to see how the PLGA degradation products interfere with the UV measurements. It is possible to see that the distribution is narrow for every size produced (span of number distribution shown, as defined by the Malvern Mastersizer software) and the encapsulation efficiency is typically high.

\section{Table 1}

\section{Changes in size during release}

In Figure 1 a typical trend of size change during release is presented. The $D(n, 0.5)$ represents the median size of the number distribution as given by the Malvern Mastersizer. Day 0 represents the particles at the end of the solidification stage, prior to filtration and separation into samples.

Figure 1

A 40 micron pore diameter membrane gives particles of $100 \mu \mathrm{m}$ diameter, a $20 \mu \mathrm{m}$ membrane gives particles in the region of 60 while a $7 \mu \mathrm{m}$ membrane gives particle around $50 \mu \mathrm{m}$, see Table 1 for details on size distributions. During the release, the particles appear to swell for a period until the polymer degradation starts and then the size decreases gradually. Towards the end 
there are not many particles left and they are not enough for the instrument (Malvern Mastersizer) to reach the minimum obscuration level required for analysis. Also, because of the change in inner morphology, the refractive index, an important parameter in laser light diffraction, was continuously changing. Measurements taken from the particle pictures by Image $\mathrm{J}$ show that the final particle size levels off at around $30 \mu \mathrm{m}$. When the particles are bigger (obtained by a $40 \mu \mathrm{m}$ membrane) they reach maximum swelling later than the smaller ones, at day 20 rather than day 15 and 13 for 7 and $20 \mu \mathrm{m}$ respectively). Typically, the beginning of the PLGA degradation is around day 10 [24]. Particles obtained by 20 and $7 \mu \mathrm{m}$ membranes behave quite similarly since they do not differ much in size at the beginning and they reach maximum swelling in the same period. Also, for the $40 \mu \mathrm{m}$ membrane particles, there appears to be a lag time before the size starts increasing. The particle size is related to the surface area-volume ratio. A small size leads to a higher ratio, hence a quicker hydration of the particles surrounded by the water medium and the swelling process starts immediately. With the smaller size, the acidic $\mathrm{pH}$ required to accelerate the degradation process is reached quicker. The acid being generated by the degradation process itself.

This change in size pattern during release is typical of particles encapsulating a water phase. Simple particles, e.g. obtained by a single emulsification, were also produced. This kind of particle would be suitable for oil soluble drugs. An oil phase made of PLGA and DCM was injected in the continuous phase (usual combination of PVA, salt and DCM) under the same conditions of when water encapsulating droplets are produced. They also underwent solidification 
and release studies following the same procedures. In Figure 2, the change in size of these particles is shown and compared with the double emulsification ones.

Figure 2

While particles obtained by a double emulsification swell up to a maximum and then their size decreases due to PLGA degradation, particles that do not encapsulate a water phase grow in size until losing their structure, see also the later optical images.

Following from the earlier study [6], the inner water phase contains a salt concentration of $40 \mathrm{~g} / \mathrm{l}$. The swelling was thought to be due to this inner salt causing an osmotic pressure between the inner water phase and the release water medium made of PBS. Salt was added to the latter to suppress the swelling. It is difficult to exactly balance the salt concentration during the release. Salt $(\mathrm{NaCl})$ is already present in the PBS solution $(8 \mathrm{~g} / \mathrm{l})$ together with other salts $\left(\mathrm{KCl}, \mathrm{Na}_{2} \mathrm{HPO}_{4}, \mathrm{KH}_{2} \mathrm{PO}_{4}\right)$. The initial inner concentration is known $(40 \mathrm{~g} / \mathrm{l})$ but during the solidification itself there is water intake. Since the drug release presents a lag time corresponding to the swelling period, suppressing the swelling should help avoid the lag time period. The results from this set of experiments were not conclusive (data not shown), in some cases swelling was still visible and they all presented a lag time in the model-drug release. As a result, the inner salt concentration during production was lowered to 13 $\mathrm{g} / \mathrm{l}$ and no salt was added to the PBS solution, to better mimic body conditions and lower the swelling, assuming it was due to the presence of an osmotic pressure. 
In Figure 3, the effect of the inner salt concentration during production, on the change in size during release, is shown. The filled markers represent particles obtained with $13 \mathrm{~g} / \mathrm{l}$ of salt in the inner and outer water phase. The empty ones are for when $40 \mathrm{~g} / \mathrm{l}$ was used in both water phases. In both case, there was no osmotic pressure during the production phase, a $40 \mu \mathrm{m}$ membrane was used and $15 \%$ PLGA. The particles were then dissolved in the same release medium. The starting size is the same, as all the conditions influencing the size are equal. The size change pattern is similar and, surprisingly, a lower amount of salt in the inner water phase leads to a higher volume swelling. It shows that swelling is not only due to osmotic pressure, due to the difference in salt concentration between the inner water phase and the PBS solution, but there must be other driving forces. Some papers report the intake of water due to osmotic pressure created by the degradation products [27].

Figure 3

The remaining aspect to consider is the PLGA concentration and the effect of osmotic pressure, Figure 4. The diamonds represent particles obtained using $15 \%$ of PLGA while the triangles are for 5\% PLGA. Using the same pore diameter membrane, $40 \mu \mathrm{m}$, two sizes are obtained by creating an inward flux of water due to the osmotic pressure during the solidification, see [6]. Once the particles are placed in the same release medium, the only effect of osmotic pressure left is a different particle structure and morphology. Comparing the grey and white diamonds in Figure 4, the initial size is different, as expected, but they follow the same size change pattern during the release. When using 5\% PLGA, there was not any lag time before the size 
started increasing, the maximum swelling was lower and the size decreased once degradation started and it was more gradual. A lower amount of polymer provides a less dense texture and the particles are, therefore, more porous. The particles become thoroughly hydrated and the swelling starts immediately, as would be expected for smaller particles. At the same time, a more porous structure allows the polymer degradation products to diffuse out more easily, lowering the acidic $\mathrm{pH}$ environment inside the particles and slowing down the degradation process. Hence, a slower decrease in size once the particles are degrading. More studies are needed to link different degradation behaviours with the cumulative drug release.

Figure 4

\section{Cumulative Drug Release}

Together with all the data presented for the change in size, data regarding the cumulative blue dextran release was collected. The data shown here gives useful information about the general behaviour, but lacks the fine precision of the particle size data. In Figure 5 the cumulative release from particles obtained with the three membrane sizes, 15\% PLGA and no osmotic pressure are shown. The dotted lines help to visualize the trend. The drug release pattern follows the usual three phases: initial burst followed by a lag time and a following release up to completion. The lag time seems to match the period of particle swelling. A release medium influx would appear to act against the drug outward flux.

Figure 5

For the mathematical modelling, because of the UV instrument properties and the results obtained from the study of the blank particles, measurements 
below $10 \mathrm{ppm}$ are not reliable. This leads to the exclusion of the data below $30 \%$ of cumulative release, which corresponds to the period of burst and lag time. Discussing only the results above the limit of $30 \%$, it is evident that smaller particles reach total release quicker than bigger particles. This is to be expected [20, 29], but it has been questioned previously [30]. The reported effects in the literature of particle size on the release are various and contrasting. Some say that the lower surface area-volume ratio (bigger particle diameter) leads to a build up of acidic products inside the particle hence a quicker degradation and release. At the same time, in the bigger particles, the drug is distributed closer to the outer surface and the drug loading is higher, increasing the apparent drug diffusivity. On the other hand, if the release is diffusion controlled, higher particle diameter should result in slower release.

\section{Model}

There have been several studies modelling the release. The first part of release is commonly considered diffusion controlled [25, 26, 31-33]. Also, in [34], it was shown that if the drug is water soluble, the release from erodible tablets follows primarily a swelling-controlled diffusion process. Most of the previous studies consider a variation of the diffusivity coefficient rather than the variation of particle size. As the degradation proceeds, the molecular weight decreases and the diffusivity coefficient increases, employing a bulk erosion system [31-33]. In the work reported here, the gradual change in size and particle morphology, see below, seems to suggest the co-existence of a surface erosion activity. The information about the changes in size during 
release generates two possible approaches for the modelling of the degradation phase. Firstly, it is possible to couple a diffusion based model for the first part with a shrinking core model for the release during the degradation of the particles. Another option is to consider the change in size of the particles both during the swelling and during the shrinking due to degradation, using in both cases a diffusion equation with a constant diffusivity.

For the diffusion based model the equations used are:

$$
\begin{aligned}
& \frac{\partial q}{\partial t}=\frac{1}{r^{2}} \frac{\partial}{\partial r}\left(D_{e f f} \cdot r^{2} \frac{\partial q}{\partial r}\right) \\
& b(t)=\frac{3 \cdot D_{e f f}}{R(t)} \frac{\partial q}{\partial r}(@ r=R) \\
& m_{b}(t)=-b(t) \cdot V_{r e l} \cdot t
\end{aligned}
$$

Initial and boundary conditions:

$q(t=0)=0.008, b(t=0)=0.008, m_{b}(t=0)=0$

$$
\frac{\partial q}{\partial r}_{\mid r=0}=0, q(r=R)=0
$$

where:

$\mathrm{q}$ is the concentration of blue dextran expressed as grams of blue dextran encapsulated divided by grams of total particle, 0.008 corresponds to 3000 ppm of blue in the initial inner water phase. For each set of data the encapsulation efficiency is considered, so the boundary conditions are not going to be 0.008 , but lower and different for each situation: according to the encapsulation efficiency. $D_{\text {eff }}$ is the effective diffusion coefficient, initially 1 e-15 $\mathrm{cm}^{2} / \mathrm{s}$, but then altered iteratively to improve the data-model agreement, $\mathrm{R}$ is the radius of the particle, $V_{r e l}$ is the volume of release medium, $b$ is the 
average concentration of blue inside the particle, $m_{b}$ is the mass of blue found in the PBS solution. $\mathrm{R}$ is expressed as an equation to consider the change in size. The particle radius in $\mathrm{cm}$ was plotted against the time of release in seconds; a linear trend line was considered by splitting the process in to two: swelling and degradation. The system was solved by using the software PDESOL (Numerica, USA), running on an XP operating system on a PC.

When considering a shrinking core based model for the second part of release the following equations were used:

$\beta=2 \cdot D_{\text {shr.core }} \cdot c *\left(\frac{6}{\rho_{p} \cdot q}\right)^{\frac{1}{3}} \cdot(\pi \cdot N)^{\frac{2}{3}}$

$m_{\text {bin }}(t)=\left[m_{b}(0)^{\frac{2}{3}}-\frac{2}{3} \cdot \beta \cdot t\right]^{\frac{3}{2}}$

where:

$D_{\text {shr.core }}$ is the coefficient of diffusivity which best fits in this situation: 1e-13 $\mathrm{cm}^{2} / \mathrm{s}, \mathrm{c}^{*}$ is the inner initial concentration of blue dextran, $\rho_{\mathrm{p}}$ is the density of the particle, taken as the density of PLGA, $q$ is the same blue concentration as expressed for the diffusion model, $N$ is the number of particles, $m_{b}(0)$ is the amount in grams of blue dextran inside the particle at time $0, m_{\text {bin }}$ is the amount of blue dextran inside the particle changing with time.

Figure 6

Figure 6 shows a reasonable model-experimental data matching. The data refers to particles obtained with a $20 \mu \mathrm{m}$ membrane, the diamonds are the experimental data and the continuous line is the model based on diffusion during the initial swelling period. Once degradation starts, the two approaches 
are compared: the line-dot curve represents the shrinking core model whilst the dotted line uses the diffusion model with the radius decreasing over time. It looks like the latter best represents the results. The shrinking core model cannot be used over periods of long release since the second part of equation 5 can become higher than the previous, leading to a negative square root. Thus, a diffusion based approach including the variation in size, seems to better represent the experimental data.

\section{Images}

For every sample, pictures with an optical microscope were taken to confirm the sizes measured by the Malvern and track any visible change. Pictures of particles obtained by a $20 \mu \mathrm{m}$ membrane, as an example, are shown. At day zero the particles look dark, spherical and monosized, Figure 7.

Figure 7

Figure 8

Figure 9

The dark colour is not due to the blue dye encapsulated since the blank particles look the same, Figure 10. The dark colour is due to the internal emulsion. The primary emulsification was obtained by a homogenizer, which generates very small droplets. As the release progresses, it is possible to see some changes, Figure 8 at day 13 and Figure 9 after 30 days.

At day 13 both the particles obtained with 7 and $20 \mu \mathrm{m}$ have already achieved their maximum swelling and degradation is starting, see also Figure 1. At day 31, Figure 9, the particles have already achieved complete release. They 
have become almost transparent, an internal boundary is visible. It may be the front of the internal degradation (bulk erosion), or thinning of the particle wall. These particles are very weak and they did not stand the drying and coating conditions used to obtain images using the FEG-SEM technique.

In bulk erosion, the expected size of the microsphere is almost constant, and the external fluid penetrates into the microsphere throughout and, thefore, internal erosion of the polymer takes place everywhere. In the surface erosion of a microsphere model, the erosion of the polymer is largely confined to the external boundary which causes the size of the microsphere to decrease gradually $[35,36]$.

PLGA degradation is an autocatalytic hydrolysis reaction. The acidic environment created by the degradation products speed up the reaction itself. The majority of studies consider oil-soluble, or solid drugs, and they perform a single emulsification. There is no water phase inside. Once in the release water medium, the porous particles take up water, the inner $\mathrm{pH}$ decreases and the degradation starts. Because of the polymer matrix the products cannot diffuse out easily and the bulk area becomes more and more acidic. The outer surface is kept neutral by the buffer, resulting in mainly bulk erosion [27]. However, when a double emulsification is performed, a water phase is present inside the particles. This water phase acts in two ways: to initiate the hydrolysis reaction but also to mildly buffer the acidity of the products generated. The bulk degradation is, therefore, slower and it is possible to notice an effect on the surface degradation too. The inner water buffer effect is shown by the fact that PLGA degradation starts slightly later than previously reported, day 11 to 20 instead of 10 [24]. The images show the effects of 
surface degradation. In [23] the authors saw PLA and PLGA surface erosion when the degradation was conducted in a basic environment.

In Figure 10 particles made by a double emulsification, but without dye (referred as blank), and particles obtained by single emulsification (referred to as simple) are shown.

Figure 10

Figure 11

Despite missing the blue dye, the blank particles are dark due to the inner structure obtained by the primary emulsification performed by a homogenizer, Figure 10a. At day 0, particles obtained by single emulsification look clear, Figure 10b. In Figure $10 \mathrm{c}$ and $\mathrm{d}$ images were taken with the FEG-SEM technique of the same particles and are shown to highlight the difference in morphology caused by the presence of the inner water phase.

Following the change in size of the simple particles, as shown in Figure 2, the inner morphology changes due to bulk erosion and it becomes progressively darker, see Figure 11. The particles become very weak and they fuse together, in agreement with the size data shown in Figure 2.

\section{Conclusions}

Membrane emulsification, using a laminar sheet membrane in a Dispersion Cell, provides a tool to obtain monosized and size controlled emulsions and particles. Varying the production parameters, it is possible to achieve high encapsulation efficiency and influence the internal porosity. Due to the significant amount of particles produced by this technique it was possible to 
study the change in size, surface morphology and drug cumulative release of the resulting particles over a prolonged period of time. The particles go through a period of swelling and water intake, corresponding to the initial burst and lag time of the drug release. Then degradation prevails and the size gradually decreases, liberating more encapsulated drug until completion. Modelling by a shrinking core approach was not successful, with poor agreement between model and data. However, a model based on diffusion, and considering the particle change in size, has been shown to follow the experimental data in reasonable agreement. The images and the size change data suggests that, together with bulk erosion, when an external water phase is present, surface erosion contributes significantly to the PLGA degradation. In this study, bulk degradation may well have been suppressed by the buffering influence of the internal water phase, reducing the acid concentration of the PLGA degradation products.

\section{References}

[1] S.R. Kosvintsev, G. Gasparini, R.G. Holdich, I.W. Cumming and M.T.

Stillwell, Liquid-liquid membrane dispersion in a stirred cell with and without controlled shear, Ind.Eng.Chem.Res. 44 (2005) 9323-9330.

[2] M.T. Stillwell, R.G. Holdich, S.R. Kosvintsev, G. Gasparini and I.W. Cumming, Stirred cell membrane emulsification and factors influencing dispersion drop size and uniformity, Ind.Eng.Chem.Res. 46 (2007) 965-972.

[3] S.R. Kosvintsev, G. Gasparini and R.G. Holdich, Membrane emulsification: droplet size and uniformity in the absence of surface shear, J. Membrane Sci. $313(1-2)(2008)$ 182-189. 
[4] M.M. Dragosavac, M.N. Sovilj, S.R. Kosvintsev, R.G. Holdich and G.T. Vladisavljević, Controlled production of oil-in-water emulsions containing unrefined pumpkin seed oil using stirred cell membrane emulsification, J. Membrane Sci., 322(1) (2008) 178-188.

[5] E. Egidi, G. Gasparini, R.G. Holdich, G.T. Vladisavljevic and S.R. Kosvintsev, Membrane emulsification using membranes of regular pore spacing: droplet size and uniformity in the presence of surface shear, J. Membrane Sci. 323 (2008) 414-420.

[6] G. Gasparini, S.R. Kosvintsev, M.T. Stillwell and R.G. Holdich, R.G., Preparation and characterization of PLGA particles for subcutaneous controlled drug release by membrane emulsification, Colloids Surf B Biointerfaces 61(2) (2008) 199-207.

[7] K.F. Pistel, B. Bittne, H. Koll, G. Winter and T. Kissel, Biodegradable recombinant human erythropoietin loaded microspheres prepared from linear and star-branched block copolymers: influence of encapsulation technique and polymer composition on particle characteristics, J. Cont. Rel. 59 (1999) 309-325.

[8] X. Wang, E. Wenk, X. Hu, G.R. Castro, L. Meinel, X. Wang, C. Li, H. Merkle and D.L. Kaplan, Silk coatings on PLGA and alginate microspheres for protein delivery, Biomaterials 28 (28) (2007) 4161-4169.

[9] M.J. Tsung and D.J. Burgess, Preparation and characterization of gelatine surface modified PLGA microspheres, AAPS PharmSci 3 (1) (2001) article 11. [10] A.O. Eniola and D.A. Hammer, Characterization of biodegradable drug delivery vehicles with the adhesive properties of leukocytes II: effect of degradation on targeting activity, Biomaterials 26 (2005) 661-670. 
[11] G. Ruan and S.S. Feng, Preparation and characterization of poly(lactic acid)-poly(ethylene glycol)-poly(lactic acid)(PLA-PEG-PLA) microspheres for controlled release of paclitaxel, Biomaterials 24 (2003) 5037-5044.

[12] A. Jaklenec, A. Hinckfuss, B. Bilgen, D.M. Ciombor, R. Aaron and E. Mathiowitz, Sequential release of bioactive IGF-I and TGF- $\beta 1$ from PLGA microsphere-based scaffolds, Biomaterials 29 (2008) 1518-1525.

[13] F.L. Mi, Y.M. Lin, Y.B. Wu, S.S. Shyu and Y.H. Tsai, Y.H., Chitin/PLGA blend microspheres as a biodegradable drug-delivery system: phaseseparation, degradation and release behaviour, Biomaterials 23 (2002) 32573267.

[14] Y.Y. Yang, H.H. Chia and T.S. Chung, Effect of preparation temperature on the characteristics and release profile of PLGA microspheres containing protein fabricated by double-emulsion solvent extraction/evaporation method, J. Cont. Rel. 69 (2000) 81-96.

[15] F. Ito, H. Fujimori and K. Makino, Incorporation of water-soluble drugs in PLGA microspheres, Colloids Surf B Biointerfaces 54 (2007) 173-178.

[16] F. Ito and K. Makino, Preparation and properties of monodispersed rifampicin-loaded poly(lactide-co-glycolide) microspheres, Colloids Surf B Biointerfaces 39(1-2) (2004) 17-21.

[17] R. Liu, G.H. Ma, Y.H. Wan and Z.G. Su, Influence of process parameters on the size distribution of PLA microcapsules prepared by combining membrane emulsification technique and double emulsion-solvent evaporation method, Colloids Surf B Biointerfaces 45 (2005) 144-153. 
[18] C. Berkland, A. Cox, K.K. Kim and D.W. Pack, Three-month, zero-order piroxicam release from monodispersed double-walled microspheres of controlled shell thickness, J. Biomed. Mater. Res. A 70A(4) (2004) 576-584.

[19] N.K. Varde and D.W. Pack, Influence of particle size and antacid on release and stability of plasmid DNA from uniform PLGA microspheres, J.Cont. Rel. 124 (2007) 172-180.

[20] C. Berkland, M. King, A. Cox, K.K. Kyekyoon and D.W. Pack, Precise control of PLG microsphere size provides enhanced control of drug release rate, J. Cont. Rel., 82 (2002) 137-147.

[21] C. Berkland, K.K. Kim and D.W. Pack, Fabrication of PLG microspheres with precisely controlled and monodisperse size distributions, J. Cont. Rel. 73 (2001) 59-74.

[22] E.J. Pollauf, K.K. Kim and D.W. Pack, Small-molecule release from Poly(D,L-lactide)/poly(D,L-lactide-co-glycolide) composite microparticles, J. Pharm. Sci. 94(9) (2005) 2013-2022.

[23] C. Dai, B. Wang and H. Zhao, Microencapsulation peptide and protein drugs delivery system, Colloids Surf B Biointerfaces 41 (2005) 117-120.

[24] A. Al-Maaieh and D.R. Flanagan, Salt and cosolvent effects on ionic drug loading into microspheres using an O/W method, J. Cont. Rel. 70 (2001) 169181.

[25] J.L. Cleland, Solvent evaporation processes for the production of controlled release biodegradable microsphere formulations for therapeutics and vaccines, Biotechnol. Prog. 14(1) (1998) 102-107. 
[26] L.K. Chiu, W.J. Chiu and Y.L. Cheng, Effects of polymer degradation on drug release - a mechanistic study of morphology and transport properties in 50:50 poly(dl-lactide-co-glycolide), Int. J. Pharm. 126 (1995) 169-178.

[27] K. Fu, D.W. Pack, A.M. Klibanov, R. Langer, R., Visual evidence of acidic environment within degrading poly(lactic-co-glycolic acid) (PLGA) microspheres, Pharm. Res. 17(1) (1999) 100-106.

[28] C. Pérez-Rodriguez, N. Montano, K. Gonzalez and K. Griebenow, Stabilization of alfa-chymotryspin at the $\mathrm{CHCl} 2 /$ water interface and upon water-in-oil-in-water encapsulation in PLGA microspheres, J. Cont. Rel. 89 (2003) 71-85.

[29] C. Berkland, K.K. Kim and D.W. Pack, PLG microsphere size controls drug release through several competing factors, Pharm. Res. 20(7) (2003) 1055-1062.

[30] J. Siepmann, N. Faisant, J. Akiki, J. Richard and J.P. Benoit, Effect of the size of biodegradable microparticles on drug release: experiment and theory. J. Cont. Rel. 96 (2004) 123-134.

[31] C. Raman, C. Berkland, K.K. Kim and D.W. Pack, Modelling smallmolecule release from PLG microspheres: effects of polymer degradation and nonuniform drug distribution, J. Cont. Rel. 103 (2005) 149-158.

[32] J.M. Bezemer, R. Radersma, D.W. Grijpma, P.J. Dijkstra, J. Feijen and C.A. van Blitterswijk, Zero-order release of lysozyme from poly(ethylene glycol)/poly(butylene terephthalate) matrices, J. Cont. Rel. 64 (2000) 179-192. [33] J.M. Bezemer, R. Radersma, D.W. Grijpma, P.J. Dijkstra, C.A. van Blitterswijk and J. Feijen, Microspheres for protein delivery prepared from 
amphiphilic multiblock copolymers. 2) Modulation of release, J. Cont. Rel. 67 (200) 249-260.

[34] I. Katzhendler, A. Hoffman, A. Golderberger and M. Friedman, Modelling of drug release from erodible tablets, J. Pharm. Sci. 86(1) (1997) 110-115.

[35] M. Zhang, Z. Yang, L.L. Chow and C.H. Wang, Simulation of drug release from biodegradable polymeric microspheres with bulk and surface erosions, J. Pharm. Sci. 92(10) (2003) 2040-2056.

[36] F. von Burkersoda, L. Schedl and A. Göpferich, A., Why degradable polymers undergo surface erosion or bulk erosion, Biomaterials 23 (2002) $4221-4231$. 
Table 2

Conditions and characterization of produced particles

\begin{tabular}{|c|c|c|c|c|c|c|c|}
\hline $\begin{array}{c}\text { Membrane } \\
\text { pore } \\
\text { diameter } \\
\mu \mathrm{m}\end{array}$ & $\begin{array}{l}\text { Inner } \\
\text { salt } \\
\text { conc } \\
\text { g/l }\end{array}$ & $\begin{array}{l}\text { Outer } \\
\text { salt } \\
\text { conc } \\
\mathrm{g} / \mathrm{l}\end{array}$ & $\begin{array}{l}\text { Salt } \\
\text { ratio }\end{array}$ & $\begin{array}{c}\text { PLGA } \\
\text { conc } \\
\%\end{array}$ & $\begin{array}{c}\text { Median } \\
\text { particle } \\
\text { size } \\
\mu \mathrm{m}\end{array}$ & span & $\begin{array}{c}\text { Encapsulation } \\
\text { efficiency }\end{array}$ \\
\hline \multirow[t]{5}{*}{40} & \multirow[t]{2}{*}{40} & \multirow[t]{2}{*}{40} & $\begin{array}{l}1 \\
1\end{array}$ & $\begin{array}{l}15 \\
15\end{array}$ & $\begin{array}{l}91 \\
86\end{array}$ & $\begin{array}{l}0.599 \\
0.437\end{array}$ & $\begin{array}{c}84 \\
\text { blank }\end{array}$ \\
\hline & & & $\begin{array}{l}1 \\
1\end{array}$ & $\begin{array}{l}5 \\
5\end{array}$ & $\begin{array}{l}85 \\
81\end{array}$ & $\begin{array}{l}0.533 \\
0.605\end{array}$ & $\begin{array}{c}85 \\
\text { blank }\end{array}$ \\
\hline & \multirow[t]{2}{*}{40} & \multirow[t]{2}{*}{13} & $1 / 3$ & 15 & 117 & 0.609 & 74 \\
\hline & & & $1 / 3$ & 5 & 111 & 0.583 & 30 \\
\hline & 13 & 13 & 1 & 15 & 95 & 0.669 & 61 \\
\hline \multirow[t]{3}{*}{20} & 40 & 40 & 1 & 15 & 36 & 0.881 & 95 \\
\hline & 40 & 13 & $1 / 3$ & 15 & 61 & 1.300 & 88 \\
\hline & 13 & 13 & 1 & 15 & 49 & 0.643 & 72 \\
\hline 7 & 13 & 13 & $\begin{array}{l}1 \\
1\end{array}$ & $\begin{array}{l}15 \\
15\end{array}$ & $\begin{array}{l}1 \\
37\end{array}$ & $\begin{array}{l}0.630 \\
0.449\end{array}$ & $\begin{array}{c}87 \\
\text { blank }\end{array}$ \\
\hline
\end{tabular}


List of Figure captions

Figure 1 Change in size during the release of particles obtained with different membrane pore size:
$\square 40 \mu \mathrm{m}$
$\triangle 20 \mu \mathrm{m}$
$7 \mu \mathrm{m}$
$\diamond 7 \mu \mathrm{m}$ repeat

Figure 2 Change in size during release of particle obtained by a $7 \mu \mathrm{m}$ membrane, encapsulating a water phase $(\mathrm{W} / \mathrm{O} / \mathrm{W})$ or obtained by a single emulsification $(\mathrm{O} / \mathrm{W})$
$\diamond \mathrm{W} / \mathrm{O} / \mathrm{W}$
$\triangle \mathrm{O} / \mathrm{W}$

Figure 3 Effect of inner salt concentration on the particle size during release
$\diamond 13 \mathrm{~g} / \mathrm{l}$
$\diamond 40 \mathrm{~g} / \mathrm{l}$

Figure 4 Effect of PLGA concentration and osmotic pressure during particle production on the change in size during release
$\diamond 15 \%, 1 / 3$
$\diamond 15 \%, 1 / 1$
$\triangle 5 \%, 1 / 3$
$\triangle 15 \%, 1 / 1$

Figure 5 Cumulative drug release from particles of different sizes, obtained by different membrane pore sizes:
$\triangle 40 \mu \mathrm{m}$
$20 \mu \mathrm{m}$
$\diamond 7 \mu \mathrm{m}$ 
Figure 6 Comparison between data and model prediction for the release from particles obtained with a $20 \mu \mathrm{m}$ membrane

$\diamond$ experimental data $\quad-$ diffusion swelling

- - - diffusion degradation $\quad$-... shrinking core

Figure 7 Images obtained by optical microscope at the end of the solidification phase. In the left column the bar indicates $100 \mu \mathrm{m}$, while in the right column the bar indicates $50 \mu \mathrm{m}$.

Figure 8 Images of the releasing particles at day 13

Figure 9 Images of the releasing particles at day 31

Figure 10 Particles obtained by a $7 \mu \mathrm{m}$ membrane, a) and c) performing a double emulsion but without blue dye in the water phase (blank) and b) and d) by single emulsification to encapsulate a hydrophobic drug (simple)

Figure 11 Change in morphology during release of particles obtained by single emulsification 


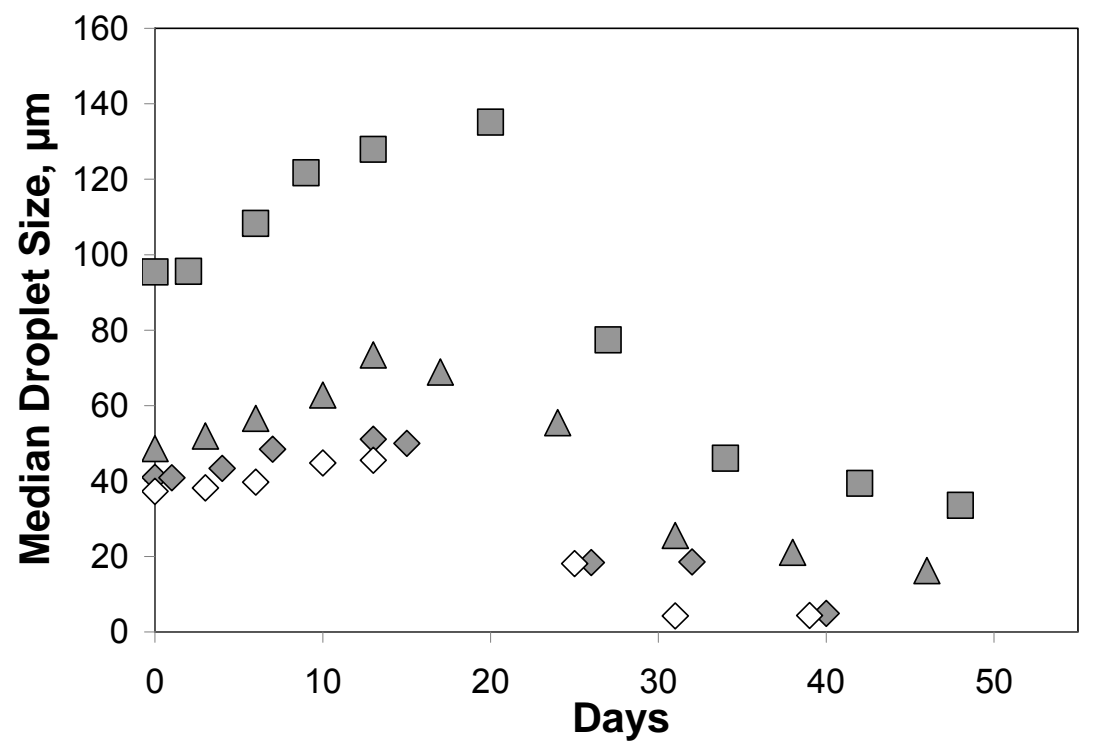

Figure 1 Change in size during the release of particles obtained with different membrane pore size:

$\square 40 \mu \mathrm{m} \quad \Delta 20 \mu \mathrm{m} \quad \diamond 7 \mu \mathrm{m} \quad \diamond 7 \mu \mathrm{m}$ repeat 


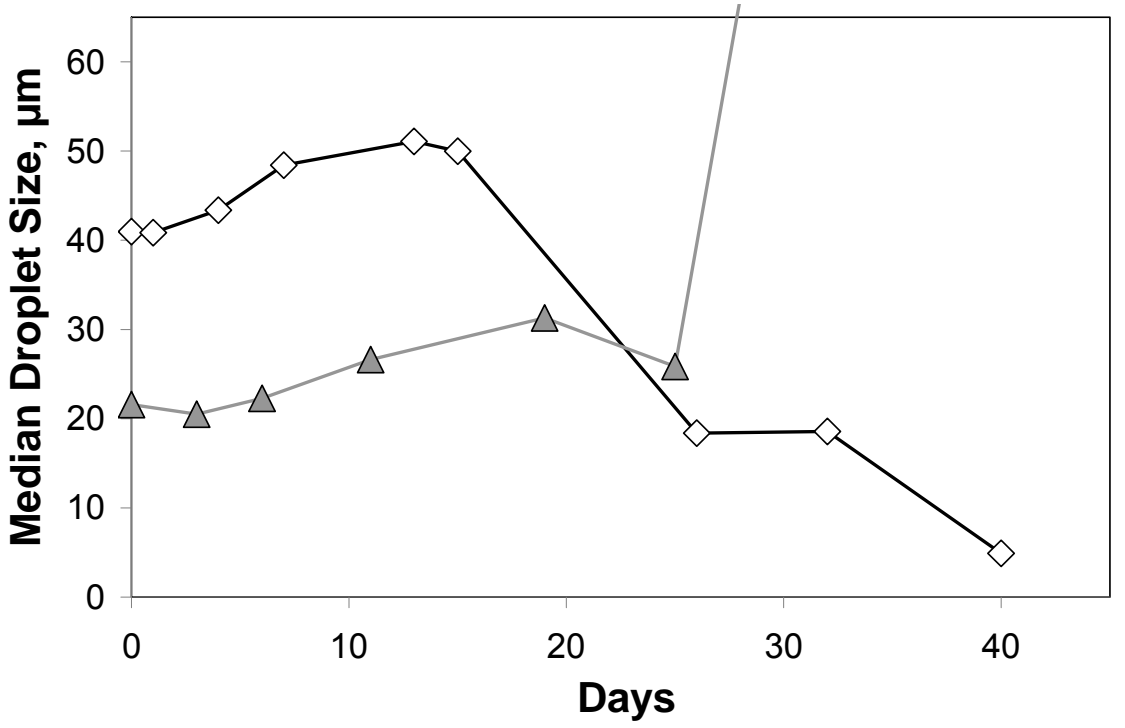

Figure 2 Change in size during release of particle obtained by a $7 \mu \mathrm{m}$ membrane, encapsulating a water phase $(\mathrm{W} / \mathrm{O} / \mathrm{W})$ or obtained by a single emulsification $(\mathrm{O} / \mathrm{W})$

$\diamond \mathrm{W} / \mathrm{O} / \mathrm{W} \quad \triangle \mathrm{O} / \mathrm{W}$ 


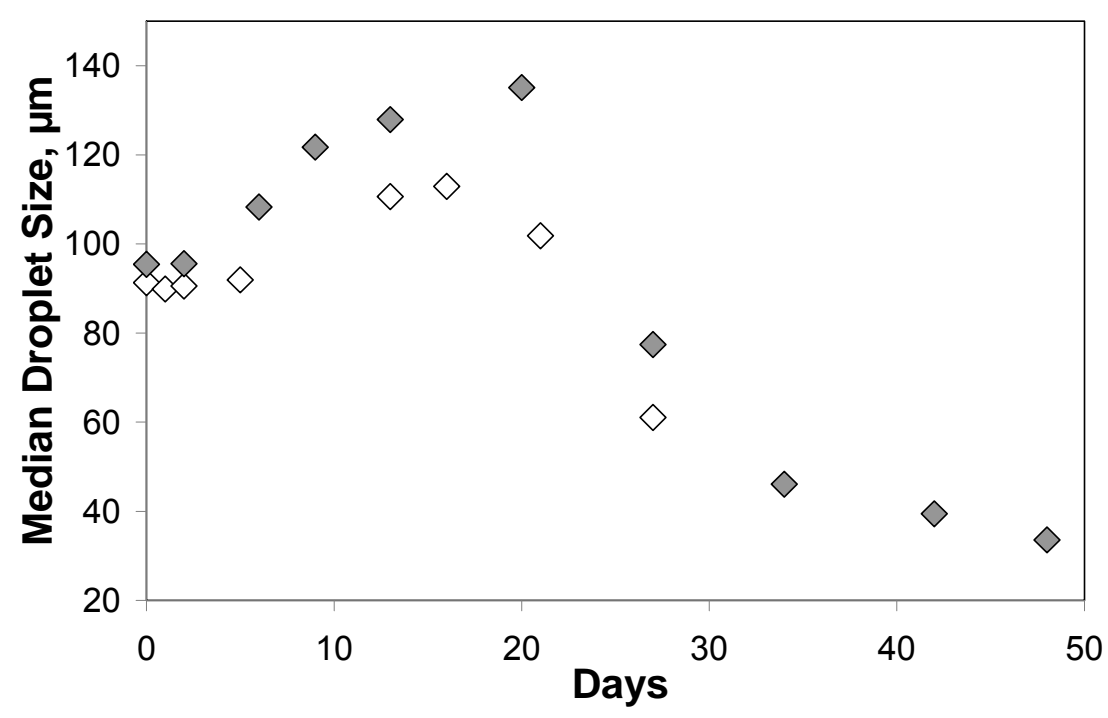

Figure 3 Effect of inner salt concentration on the particle size during release
$\diamond 13 \mathrm{~g} / \mathrm{l}$
$\diamond 40 \mathrm{~g} / \mathrm{l}$ 


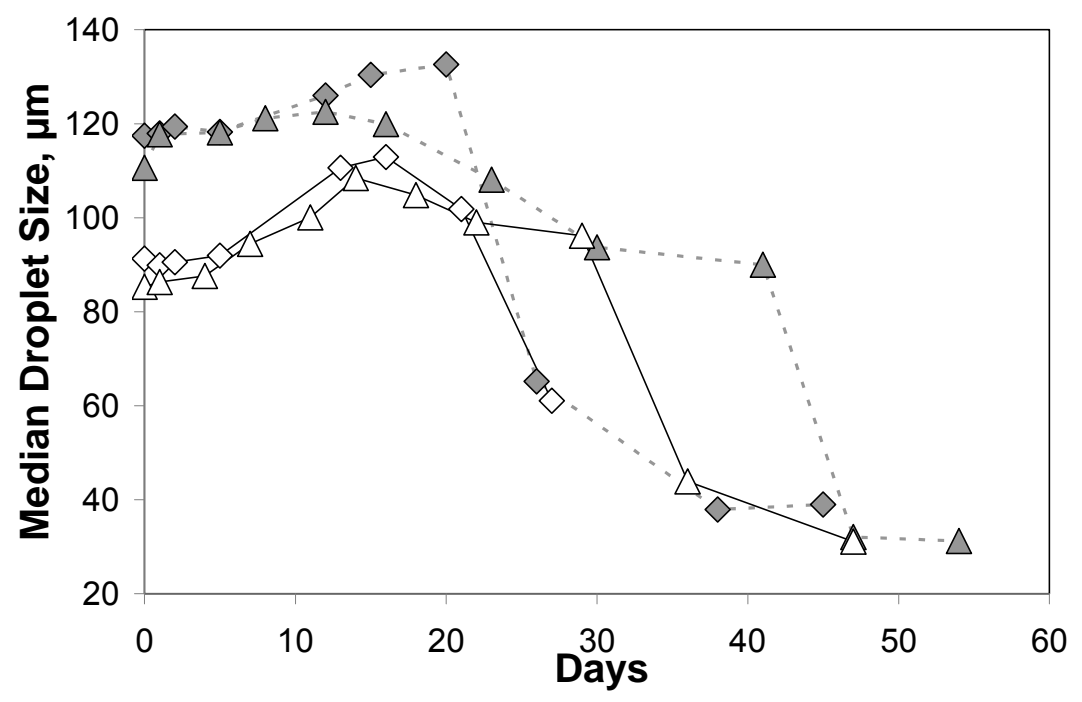

Figure 4 Effect of PLGA concentration and osmotic pressure during particle production on the change in size during release $\diamond 15 \%, 1 / 3 \diamond 15 \%, 1 / 1 \triangle 5 \%, 1 / 3 \quad \triangle 15 \%, 1 / 1$ 


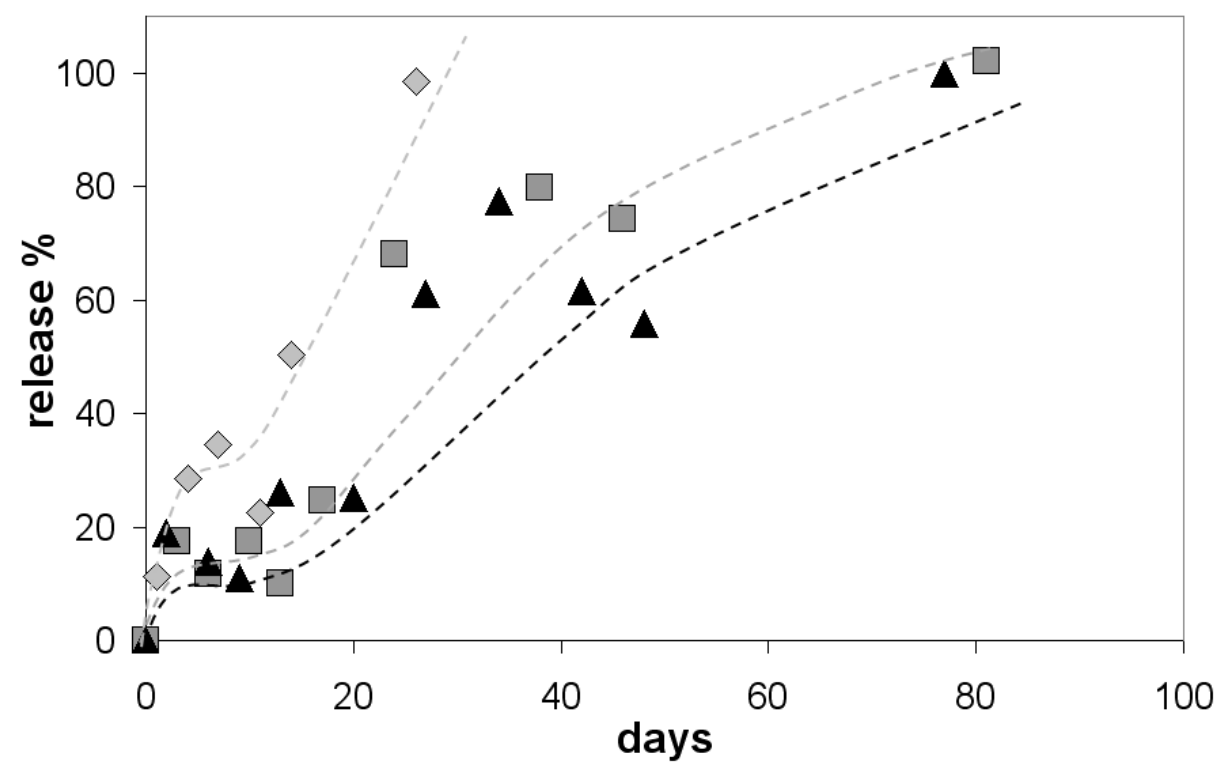

Figure 5 Cumulative drug release from particles of different sizes, obtained by different membrane pore sizes:
$\Delta 40 \mu \mathrm{m}$
$20 \mu \mathrm{m}$
$\diamond 7 \mu \mathrm{m}$ 


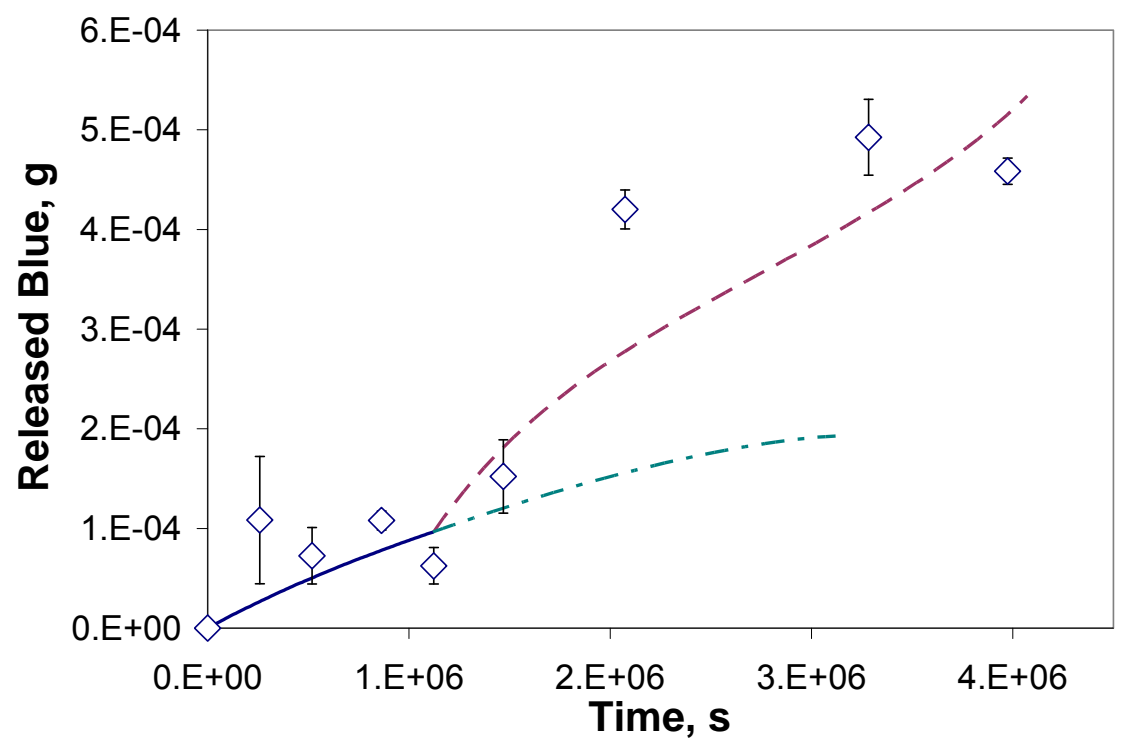

Figure 6 Comparison between data and model prediction for the release from particles obtained with a $20 \mu \mathrm{m}$ membrane $\diamond$ experimental data $\quad-$ diffusion swelling

- - - diffusion degradation _... shrinking core 


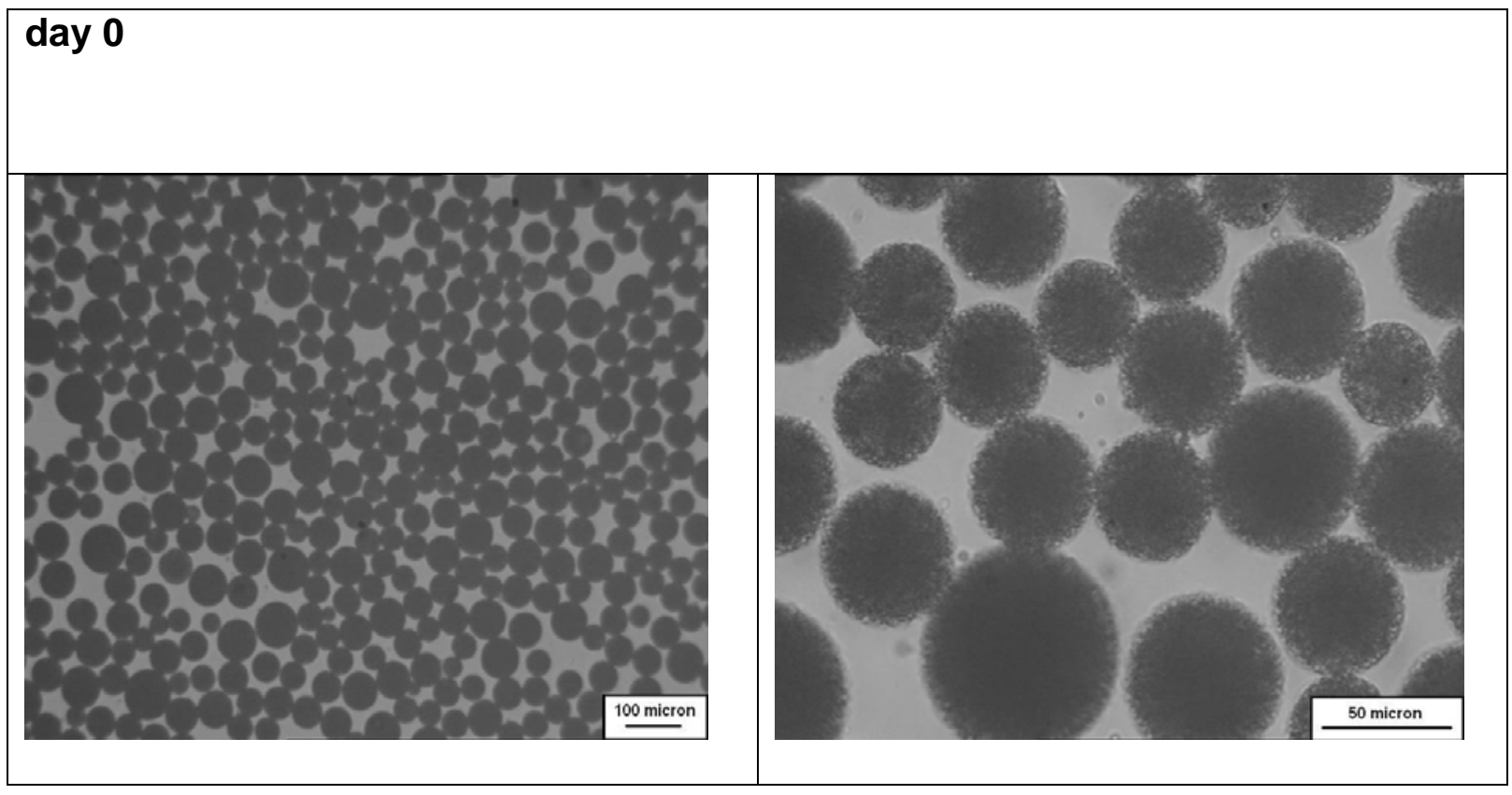

Figure 7 Images obtained by optical microscope at the end of the solidification phase. In the left column the bar indicates $100 \mu \mathrm{m}$, while in the right column the bar indicates $50 \mu \mathrm{m}$. 


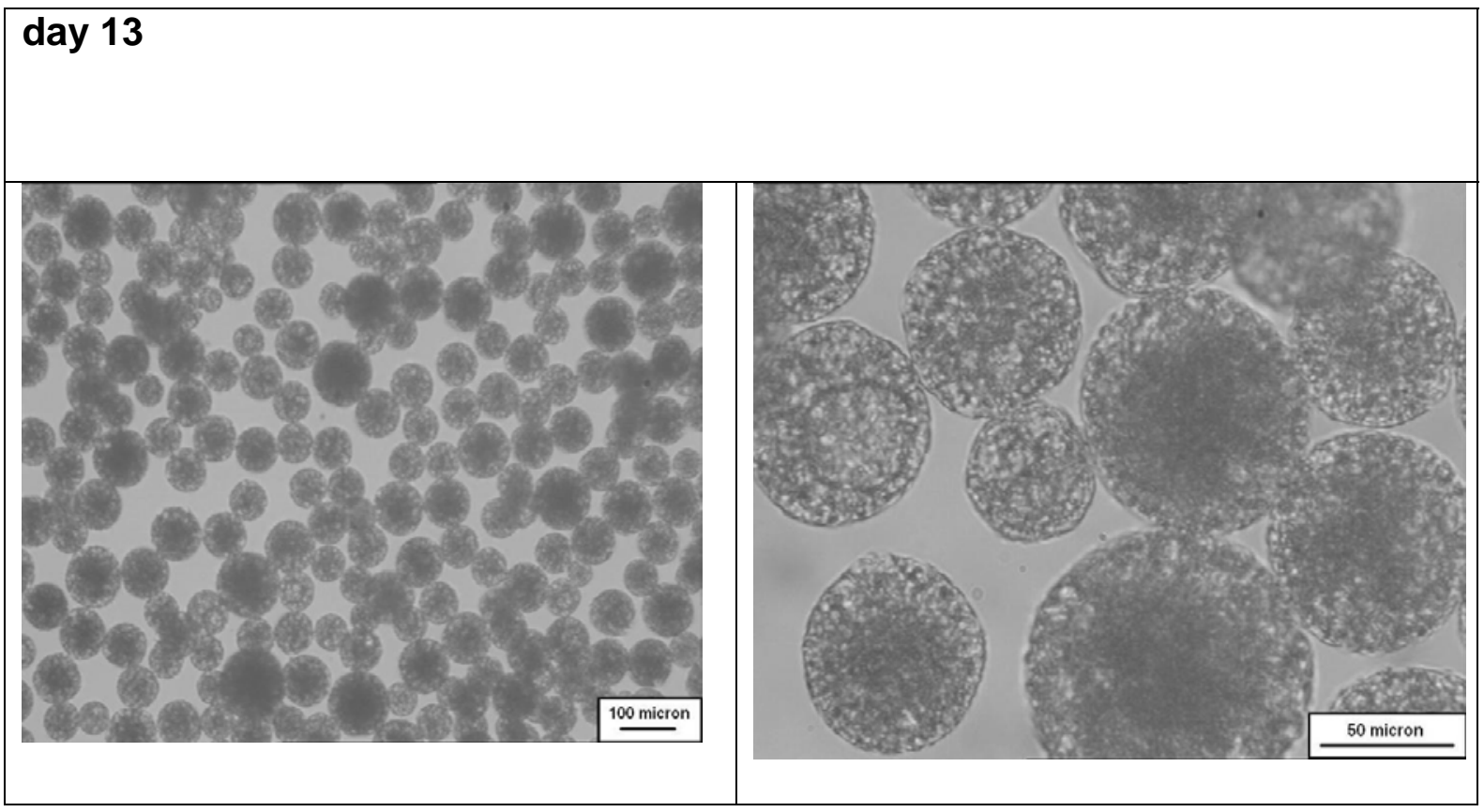

Figure 8 images of the releasing particles at day 13 


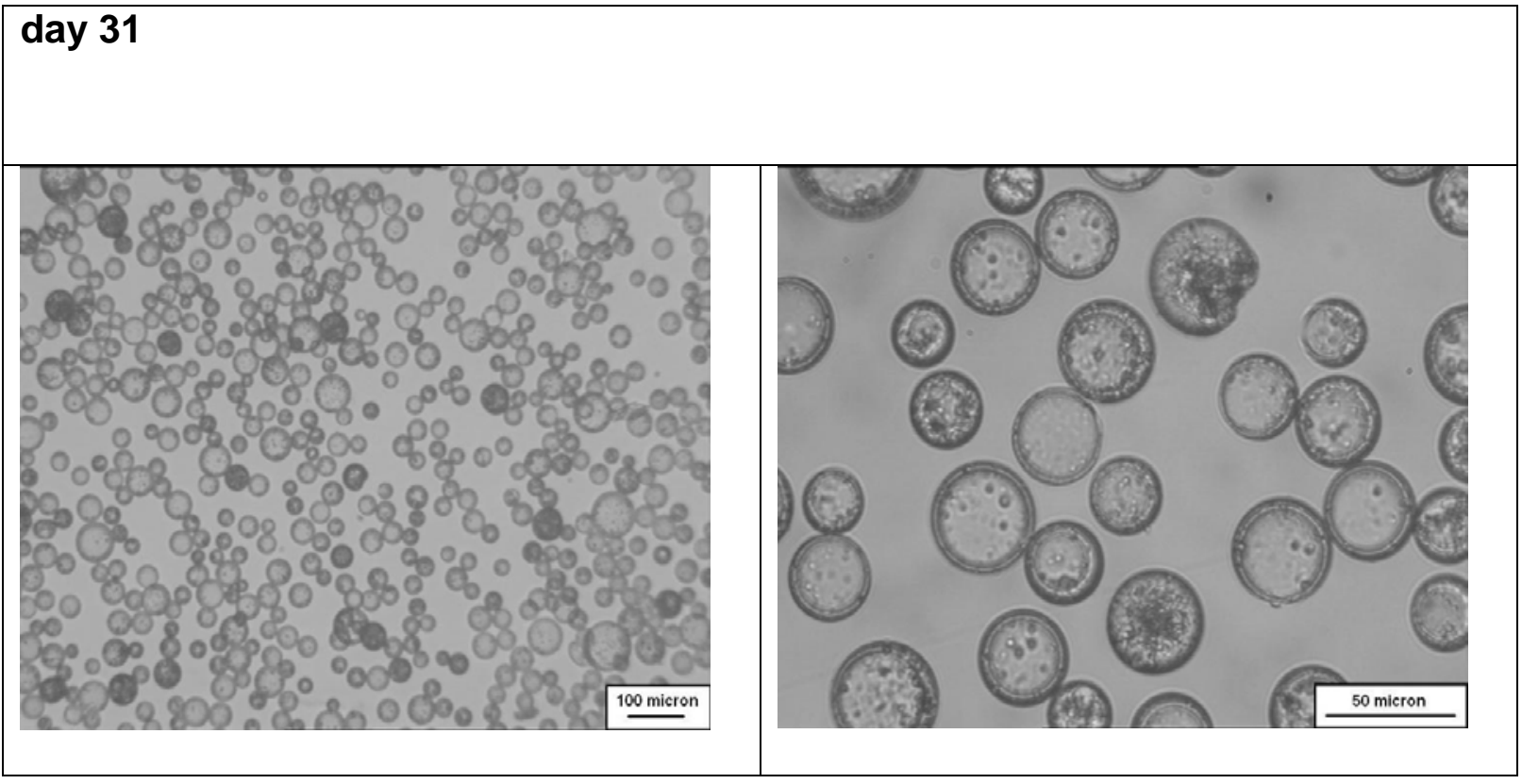

Figure 9 images of the releasing particles at day 31 


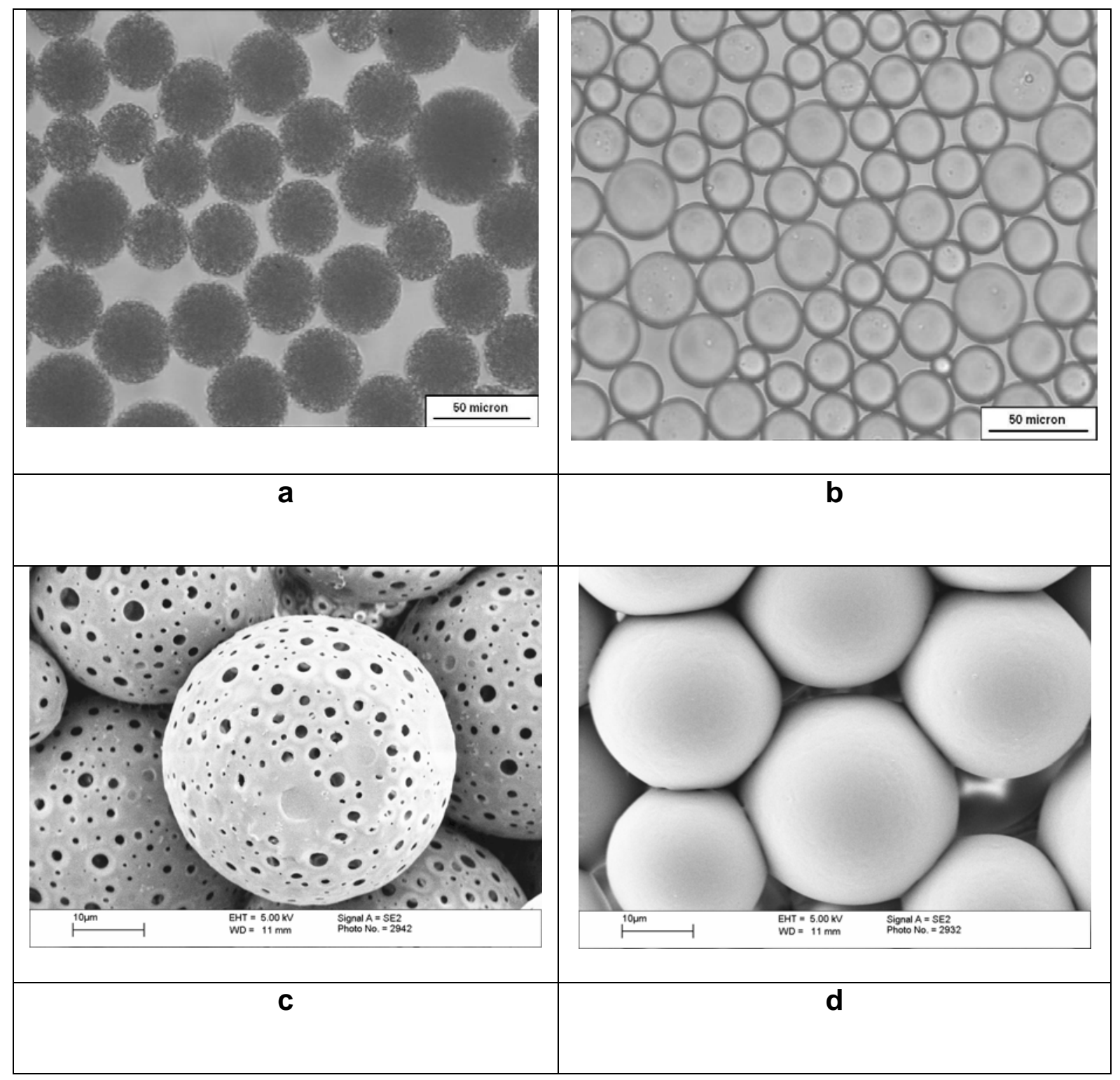

Figure 10 Particles obtained by a $7 \mu \mathrm{m}$ membrane, a) and c) performing a double emulsion but without blue dye in the water phase (blank) and b) and d) by single emulsification to encapsulate $a$ hydrophobic drug (simple) 


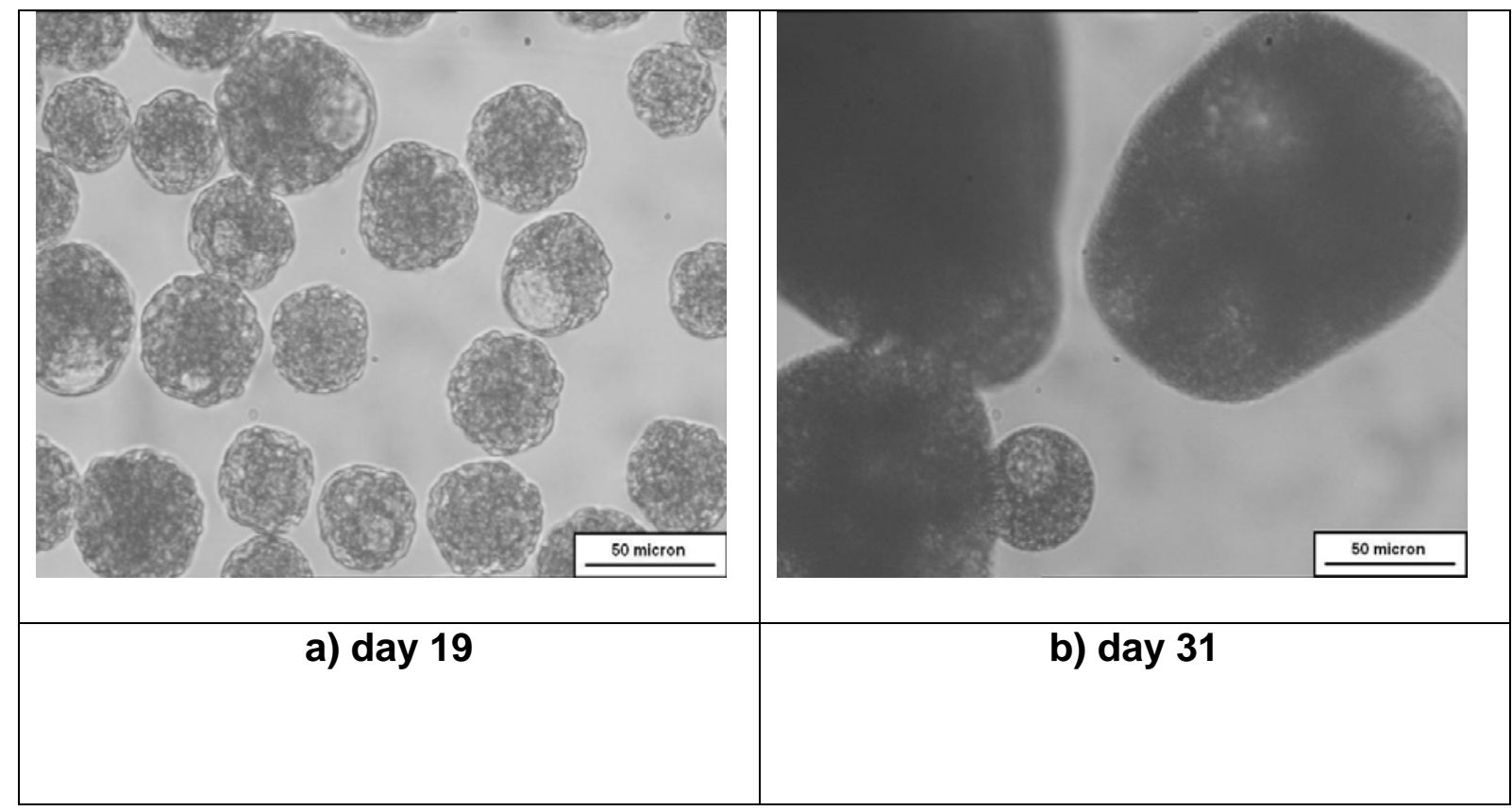

Figure 11 Change in morphology during release of particles obtained by single emulsification 